\title{
High-potency cannabis and the risk of psychosis
}

Marta Di Forti, Craig Morgan, Paola Dazzan, Carmine Pariante, Valeria Mondelli, Tiago Reis Marques, Rowena Handley, Sonija Luzi, Manuela Russo, Alessandra Paparelli, Alexander Butt, Simona A. Stilo, Ben Wiffen, John Powell and Robin M. Murray

\section{Background}

People who use cannabis have an increased risk of psychosis, an effect attributed to the active ingredient $\Delta$ 9tetrahydrocannabinol $(\Delta 9-\mathrm{THC})$. There has recently been concern over an increase in the concentration of $\triangle 9$-THC in the cannabis available in many countries.

\section{Aims}

To investigate whether people with a first episode of psychosis were particularly likely to use high-potency cannabis.

\section{Method}

We collected information on cannabis use from 280 cases presenting with a first episode of psychosis to the South London \& Maudsley National Health Service (NHS) Foundation Trust, and from 174 healthy controls recruited from the local population.

\section{Results}

There was no significant difference between cases and controls in whether they had ever taken cannabis, or age at first use. However, those in the cases group were more likely to be current daily users $(O R=6.4)$ and to have smoked cannabis for more than 5 years $(O R=2.1)$. Among those who used cannabis, 78\% of the cases group used high-potency cannabis (sinsemilla, 'skunk') compared with $37 \%$ of the control group (OR 6.8).

\section{Conclusions}

The finding that people with a first episode of psychosis had smoked higher-potency cannabis, for longer and with greater frequency, than a healthy control group is consistent with the hypothesis that $\Delta 9$-THC is the active ingredient increasing risk of psychosis. This has important public health implications, given the increased availability and use of highpotency cannabis.

\section{Declaration of interest}

None.
During the last quarter of the 20th century recreational use of cannabis increased greatly across the world. ${ }^{1}$ Cannabis consumption came to be seen as a normal leisure activity, and was regarded as safe even by the medical establishment. ${ }^{2}$ However, in recent years there has been considerable controversy over the use of cannabis, with, for example, the UK government repeatedly reviewing its safety. ${ }^{3}$ This concern has arisen from large prospective epidemiological studies which have reported that use of cannabis increases the risk of schizophrenia-like psychosis. ${ }^{4,5}$ However, these studies have not collected detailed data on the patterns of use or potency of the cannabis used, which may be important factors moderating the associated risk. ${ }^{6}$

The principal constituents of cannabis are $\Delta 9$-tetrahydrocannabinol $(\Delta 9$-THC) and cannabidiol. The former is the main psychoactive ingredient and in experimental studies it produces transient psychotic symptoms and impaired memory in a dosedependent manner. ${ }^{6,7}$ In contrast, cannabidiol does not induce hallucinations or delusions, and it seems to antagonise the cognitive impairment and psychotogenic effects caused by $\Delta$ 9-THC. ${ }^{6}$

Until the early 2000s the most freely available type of cannabis in the UK was cannabis resin ('hash'), which had approximately $70 \%$ of the 'street' market, followed by traditional imported herbal cannabis and then sinsemilla ('skunk'). Cannabis resin contains $2-4 \% \Delta 9$-THC and a similar proportion of cannabidiol, whereas herbal cannabis contains a similar percentage of $\Delta 9$-THC but no cannabidiol. ${ }^{8,9}$ However, sinsemilla (skunk) has increasingly taken over the UK market and its THC concentration, and to a lesser extent that of imported herbal cannabis, has been consistently rising. For example, seizures of cannabis on the streets of England in 2008 by the police showed that sinsemilla had a market share of more than $70 \%$, and had reached a $\Delta 9$-THC concentration of $12-18 \%$ with virtually no cannabidiol. ${ }^{8,9}$

Smith has suggested that such high-potency cannabis might be especially harmful to mental health. ${ }^{10}$ We therefore compared patterns and types of cannabis use in people experiencing their first episode of psychosis and in a healthy control sample. Specifically, we sought to test the hypothesis that daily use of high-potency cannabis is associated with a particularly high risk of psychosis.

\section{Method}

\section{Sample}

We approached all patients aged 18-65 years who presented with a first episode of psychosis to the Lambeth, Southwark and Croydon adult in-patient units of the South London \& Maudsley Mental Health National Health Service (NHS) Foundation Trust between December 2005 and October 2008. We validated clinical diagnosis by administering the Schedules for Clinical Assessment in Neuropsychiatry (SCAN). ${ }^{11}$ Patients who met ICD-10 criteria for a diagnosis of psychosis (codes F20-F29 and F30-F33) ${ }^{12}$ were invited to participate in the study; cases with a diagnosis of organic psychosis were excluded. During the same period we recruited a healthy control group $(n=174)$ from the local population living in the area served by the Trust, by means of internet and newspaper advertisements, and distribution of leaflets at train stations, shops and job centres. Cannabis was not mentioned in these advertisements. Particular attention was directed to attempting to obtain a control sample similar to the patient sample in age, gender, ethnicity, educational qualifications and employment status. Those who agreed to participate were administered the Psychosis Screening Questionnaire, ${ }^{13}$ and excluded if they met criteria for a psychotic disorder or reported a previous diagnosis of psychotic illness.

Ethical permission was obtained from the Trust and the Institute of Psychiatry research ethics committee. All study participants signed a consent form allowing publication of data originating from the study. 


\section{Assessment}

We collected sociodemographic data (age, gender, self-rated ethnicity, level of education achieved and employment status) on both cases and controls. All participants were asked about their use of illicit drugs and those who reported ever using cannabis were interviewed using the Cannabis Experience Questionnaire. ${ }^{14}$ This allows a detailed assessment of lifetime patterns of cannabis and stimulant use, including age at first use, frequency and duration of use, and the specific type of cannabis used.

\section{Statistical analysis}

Logistic regression was used to analyse the relationships between various aspects of cannabis use (lifetime use, age at first use, duration and frequency of use, and cannabis potency) and casecontrol status, and to test for interaction effects while controlling for potential confounders. Associations are expressed as odds ratios.

\section{Results}

We found 340 patients with first-episode psychosis who met our inclusion criteria. Of these patients $60(17.6 \%)$ refused to participate, leaving 280 cases to be included in our analyses. Most common reasons for refusal included lack of interest in research and the length of our study assessment. If patients initially refused because they were too ill, we approached them again later in case their refusal was simply due to the severity of their symptoms. During the same period we recruited 174 individuals to the control group. There was no significant difference between the cases and control groups in age, gender, ethnicity, educational qualifications or employment status at time of assessment (Table 1).

\section{Lifetime cannabis use}

More than half of the cases group (57\%, $n=159)$ had used cannabis at least once in their life (Table 2), compared with 109 controls $(63 \%)(\mathrm{OR}=0.8,95 \%$ CI $0.6-1.5)$. Among those who had ever used cannabis, $65 \%(n=183)$ of the cases group had first tried cannabis before the age of 17 years, compared with $52 \%$ $(n=91)$ of the control group (adjusted OR $=1.1,95 \%$ CI $0.8-3.4)$

\section{Patterns of cannabis use}

Among those who used cannabis, 59\% $(n=94)$ of the cases group had used it for more than 5 years compared with 38\% $(n=41)$ of controls (unadjusted $\mathrm{OR}=2.4,95 \%$ CI $1.2-4.7$ ). When potential confounders (age, gender, ethnicity, level of education achieved and employment status) were adjusted for, this difference was attenuated slightly (adjusted $\mathrm{OR}=2.1,95 \%$ CI $0.9-8.4$ ) and no longer reached statistical significance. However, those in the cases group were around six times more likely than the control group to use cannabis every day, even after adjusting for the above potential confounders (cases $77 \%$ v. controls $33 \%$; unadjusted $\mathrm{OR}=6.7$, 95\% CI 2.0-11.5, adjusted OR $=6.4,95 \%$ CI 3.2-28.6).

\section{Type of cannabis used}

Again considering only those who used cannabis, $78 \%(n=125)$ of the cases group preferentially used sinsemilla (skunk) compared with only $31 \% \quad(n=41)$ of the control group (unadjusted $\mathrm{OR}=8.1,95 \%$ CI 4.6-13.5). This association was only slightly attenuated after controlling for potential confounders (adjusted $\mathrm{OR}=6.8,95 \%$ CI 2.6-25.4).

\begin{tabular}{|c|c|c|}
\hline & $\begin{array}{c}\text { Cases } \\
(n=280)\end{array}$ & $\begin{array}{l}\text { Controls } \\
(n=174)\end{array}$ \\
\hline Age, years: mean (s.d.) & $25(6.9)$ & $27(5.6)$ \\
\hline \multicolumn{3}{|l|}{ Gender, $n(\%)$} \\
\hline Male & $202(72.0)$ & $113(65.0)$ \\
\hline Female & $78(28.0)$ & $61(35.0)$ \\
\hline \multicolumn{3}{|l|}{ Ethnicity, $n$ (\%) } \\
\hline White & $118(42.0)$ & $77(44.5)$ \\
\hline Black Caribbean & $60(21.5)$ & $34(19.2)$ \\
\hline Black African & $62(22.3)$ & $29(16.8)$ \\
\hline Other & $40(14.2)$ & $34(19.5)$ \\
\hline \multicolumn{3}{|l|}{ Employment, $n$ (\%) } \\
\hline Unemployed & $164(58.4)$ & 75 (43.2) \\
\hline Employed & $116(41.6)$ & $99(56.8)$ \\
\hline \multicolumn{3}{|l|}{ Education, $n$ (\%) } \\
\hline No qualification & 41 (14.6) & 19 (10.9) \\
\hline Any qualification & $239(85.4)$ & $155(88.1)$ \\
\hline
\end{tabular}

\section{Combined effects of frequency and type of cannabis use}

There was some evidence of an interaction between frequency and type of cannabis use: among those who used cannabis, those who used sinsemilla (skunk) less frequently (not every day) were around 5 times more likely to be in the cases group $(\mathrm{OR}=5.7$, 95\% CI 2.5-12.6), whereas those who used it daily were around 12 times more likely to be in the cases group $(\mathrm{OR}=12.1,95 \%$ CI 3.7-37.3; Mantel-Haenszel test for homogeneity of odds ratios: $\left.\chi^{2}=1.2, P=0.5\right)$. The variation in odds ratios was non-significant, and we consequently did not fit an interaction term to our final logistic regression model. However, this lack of significance may be due to limited statistical power, and given that the difference is in the expected direction (i.e. highest odds in those who used sinsemilla/skunk daily), the finding remains noteworthy and certainly merits further investigation.

\section{Discussion}

Patients experiencing a first episode of psychosis were not more likely to have ever taken cannabis or to have started doing so earlier than the control group. This is not surprising because cannabis consumption is very common among adolescents in the UK: $40 \%$ of British children aged 15-16 years have used cannabis. ${ }^{1}$ However, psychosis was associated with more frequent and longer use of cannabis. This confirms previous suggestions

Table 2 Lifetime cannabis use

\begin{tabular}{|c|c|c|c|c|}
\hline & \multirow{2}{*}{$\begin{array}{l}\text { Cases, } \\
\begin{array}{c}n=280 \\
n(\%)\end{array}\end{array}$} & \multirow{2}{*}{$\begin{array}{c}\text { Controls, } \\
n=174 \\
n(\%)\end{array}$} & \multicolumn{2}{|c|}{ Odds ratio $(95 \% \mathrm{Cl})$} \\
\hline & & & Unadjusted & Adjusted $^{\mathrm{a}}$ \\
\hline \multicolumn{5}{|l|}{ Ever used } \\
\hline No & $121(43.1)$ & 65 (37.5) & 1.0 & \\
\hline Yes & $159(56.9)$ & 109 (62.5) & $0.8(0.6-1.5)$ & \\
\hline \multicolumn{5}{|l|}{ Age at first use ${ }^{b}$} \\
\hline Under 17 years & 103 (65.3) & 57 (52.2) & $1.7(1.0-4.7)^{\star}$ & $1.1(0.8-3.4)$ \\
\hline 17 years and over & $56(34.7)$ & $52(47.8)$ & 1.0 & \\
\hline \multicolumn{5}{|c|}{$\begin{array}{l}\text { a. Adjusted for age, gender, ethnicity, other stimulant use, level of education } \\
\text { achieved and employment status. } \\
\text { b. In those who had ever used cannabis. } \\
* P<0.05 \text {. }\end{array}$} \\
\hline
\end{tabular}




\begin{tabular}{|c|c|c|c|c|}
\hline & \multirow{2}{*}{$\begin{array}{c}\text { Cases, } n=159 \\
n(\%)\end{array}$} & \multirow{2}{*}{$\begin{array}{c}\text { Controls, } n=109 \\
n(\%)\end{array}$} & \multicolumn{2}{|c|}{ Odds ratio $(95 \% \mathrm{Cl})$} \\
\hline & & & Unadjusted & Adjusted $^{\mathrm{a}}$ \\
\hline \multicolumn{5}{|l|}{ Duration of use } \\
\hline 0-5 years & $65(40.8)$ & $68(62.5)$ & 1.0 & 1.0 \\
\hline Over 5 years & $94(59.2)$ & $41(37.5)$ & $2.4(1.2-4.7)$ & $2.1(0.9-8.4)^{*}$ \\
\hline \multicolumn{5}{|l|}{ Frequency of use } \\
\hline every day & $37(23.1)$ & $73(66.7)$ & 1.0 & 1.0 \\
\hline Every day & $122(76.9)$ & $36(33.3)$ & $6.7(2.0-11.5)$ & $6.4(3.2-28.6)^{\star}$ \\
\hline \multicolumn{5}{|l|}{ Type used } \\
\hline Resin (hash) and traditional imported herbal cannabis ( $\triangle 9-\mathrm{THC}$ and CBD both $1 \%$ ) & $34(21.6)$ & $68(62.6)$ & 1.0 & 1.0 \\
\hline Sinsemilla (skunk) ( $\triangle 9-$ THC $12-18 \% ;$ CBD 0\%) & $125(78.4)$ & $41(37.4)$ & $8.1(4.6-13.5)$ & $6.8(2.6-25.4)^{\star}$ \\
\hline \multicolumn{5}{|c|}{$\begin{array}{l}\text { CBD, cannabidiol; } \triangle 9 \text {-THC, } \Delta 9 \text {-tetrahydrocannabinol. } \\
\text { a. Adjusted for age, gender, ethnicity, other stimulant use, level of education achieved and employment status. } \\
{ }^{\prime} P<0.05 \text {. }\end{array}$} \\
\hline
\end{tabular}

that the risks of both transient psychotic symptoms and schizophrenia in those who use cannabis are dose-related. ${ }^{6}$

Our most striking finding is that patients with a first episode of psychosis preferentially used high-potency cannabis preparations of the sinsemilla (skunk) variety. In south-east London this form of cannabis is estimated to contain between $12 \%$ and $18 \%$ $\triangle 9$-THC and less than $1.5 \%$ cannabidiol. In contrast, those in the control group who used cannabis were more likely to consume resin (hash), with an average $\Delta 9$-THC concentration of 3.4\% and a similar proportion of cannabidiol. ${ }^{9}$

It is not surprising that the higher concentration of $\Delta 9$-THC in sinsemilla (skunk) is more likely to have detrimental effects on mental health. An experimental study in normal humans of the acute effects of intravenous administration of $\Delta 9$-THC found that the resulting psychotic symptoms were dose-dependent. ${ }^{7}$ Furthermore, a positron emission tomographic study has shown that inhalation of $\triangle 9$-THC acutely increases striatal dopamine, ${ }^{15}$ which is thought to underlie psychotic symptoms. ${ }^{16}$

The relative lack of cannabidiol in sinsemilla (skunk) may also be relevant, as there is some evidence that cannabidiol has antipsychotic properties. ${ }^{17}$ Furthermore, Curran et al measured cannabinoid traces in the hair of three groups of normal volunteers, and found that those with $\triangle 9$-THC only had higher levels of schizophrenia-like symptoms than the ' $\Delta 9$-THC plus cannabidiol' and 'no cannabinoid' groups. ${ }^{18}$

The availability of skunk on the UK market has steadily increased over the past 6 years. ${ }^{8}$ Our estimate of preferred type of cannabis used refers not to current use but lifetime use. In fact, we did ask our participants to indicate among a list of types of cannabis the one they preferentially smoked at any time during their period of use. Most of those in the cases group (65\%) and control group (52\%) had started using cannabis before age 17 , on average 6 years ago, and had continued to use it for 5 years. Given that participants in the control group who used cannabis had been exposed to the same changes in the cannabis market as those from the cases group, the increased availability of skunk cannot alone explain why our control group members are less likely to prefer higher-potency types than the cases group across time.

Finally, our results suggest that the potency and frequency of cannabis use may interact in further increasing the risk of psychosis.

\section{Limitations and strengths}

Our findings need to be considered in the light of potential limitations. In theory, it is possible that our use of non-random strategies of control recruitment could have biased our findings.
However, the cases and control groups were similar on a number of sociodemographic factors that are associated with cannabis use (e.g. education) and there was no evidence that our approach undersampled those who used cannabis. Indeed, the proportion of controls who had ever used cannabis (62\%) was higher than the national average (47\%) for similar age groups, ${ }^{19}$ reflecting the fact that cannabis use is more common in south-east London than in the UK as a whole. Alternatively, if our sampling strategy resulted in oversampling those who used cannabis, this would have had the effect of reducing the strength of the associations we observed - that is, our findings would underestimate the effects of different patterns of cannabis use on the risk of schizophrenia.

Is it possible that our control recruitment strategy biased our sample towards one of mild cannabis users, excluding heavy users perhaps more likely to use skunk? Our advertising strategy included internet and local newspapers advertisements as well as distribution of leaflets at local shops, job centres and community centres. There is no evidence that such methods of advertising are more likely to bias towards better-functioning and socially adjusted individuals; indeed, the opposite might be the case. It therefore seems unlikely that the striking difference in type of cannabis used between the cases and control groups is driven by a recruitment bias. Moreover, there was no reported evidence of skunk dependence in the clinical record of cases recruited.

We cannot totally exclude the possibility that patients in a prodromal phase might need higher concentrations of $\Delta 9$-THC. However, a recent population study has shown that cannabis use in adolescence is associated with a twofold increase in prodromal symptoms even when controlling for several confounders, including behavioural symptoms. ${ }^{20}$ We also know from experimental studies that $\triangle 9$-THC is the active ingredient in inducing psychotic symptoms and that cannabidiol produces beneficial effects, including possible amelioration of psychotic symptoms and reduced anxiety. ${ }^{7,17}$ Therefore, it remains unclear why those already experiencing prodomal and/or psychotic symptoms should choose to use a cannabis type (sinsemilla) with high levels of $\triangle 9$-THC which is likely to exacerbate their symptoms, rather than one that contains as much cannabidiol as $\Delta 9$-THC (resin).

Finally, we did not have a biological measure of the type of cannabis used, such as urine, blood or hair samples. These methods allow one to test only for recent use, and would not have helped to confirm the type of cannabis used over past years. Moreover, participants in our first-episode psychosis group were in-patients at time of recruitment, and such biological tests could have produced false results for those tested more than 4 weeks after admission to hospital. A biological measure would therefore not have helped to enhance our findings. 


\section{Study implications}

It is generally accepted that drinking a glass of light wine every day is less likely to be associated with serious health consequences than drinking a daily bottle of whisky or vodka. Unfortunately, previous studies of the association between cannabis use and psychosis have not collected detailed information on the patterns of use, or potency, of the cannabis smoked. Our findings are the first to suggest that the risk of psychosis is much greater among people who are frequent cannabis users, and among those using sinsemilla (skunk) rather than occasional users of traditional hash. It is not surprising that those who use skunk daily seem to be the group with the highest risk of all.

Unfortunately, sinsemilla (skunk) is displacing traditional cannabis preparations in many countries. Public education about the risks of heavy use of high-potency cannabis is vital.

Marta Di Forti, MD, MRCPsych, Craig Morgan, MSC, PhD, Paola Dazzan, MSC PhD, MRCPsych, Carmine Pariante, MRCPsych, Valeria Mondelli, MD, PhD, Tiago Reis Marques, MD, Rowena Handley, BSC (Psychology), Sonija Luzi, BSC (Psychology), Manuela Russo, BSC (Psychology), Alessandra Paparelli, MD, Institute of Psychiatry, London; Alexander Butt, MD, MRCPsych, Springfield University Hospital, St George's and South West Thames NHS Trust, London; Simona A. Stilo, MD, Ben Wiffen, BSC (Psychology), John Powell, MA, DPhil, Robin M. Murray, MD, DSC, FRCP, FRCPsych, FMedSci, Institute of Psychiatry, London, UK

Correspondence: Dr Marta Di Forti, Department of Psychiatry, Institute of Psychiatry, De Crespigny Park, London SE5 8AF, UK. Email: m.diforti@iop.kcl.ac.uk

First received 21 Jan 2009, final revision 12 May 2009, accepted 9 Jun 2009

\section{Funding}

The study was funded by the Maudsley Charitable Fund and a UK National Institute of Health Research Biomedical Research Centre grant (BRC-SLAM).

\section{Acknowledgements}

The authors gratefully acknowledge the help of the Genetic and Psychosis study team, South London \& Maudsley Mental Health NHS Trust, Dr Paddy Power, consultan psychiatrist, Lambeth Early Onset Psychosis team, the UK National Institute of Health psychiatrist, Lambeth Early Onset Psychosis team, the UK National Institute of Health
Research Biomedical Research Centre and the Institute of Psychiatry, King's college Rosearch

\section{References}

1 United Nations Office on Drugs and Crime. UNODC World Drug Report (http://www.unodc/org/unodc/en/data-and-analysis/WDR.2006.html).
2 Deglamorising cannabis. Lancet 1995; 346: 1241

3 Advisory Council on the Misuse of Drugs. The Classification of Cannabis under the Misuse of Drugs Act 1971. Home Office, 2005.

4 Henquet $C$, Murray R, Linszen $D$, van Os J. The environment and schizophrenia: the role of cannabis use. Schizophr Bull 2005; 31: 608-12.

5 Moore TH, Zammit S, Lingford-Hughes A, Barnes TRE, Jones PB, Burke M, et al. Cannabis use and risk of psychotic or affective mental health outcomes: a systematic review. Lancet 2007; 370: 319-28.

6 Murray MR, Morrison PD, Henquet C, Di Forti M. Cannabis, the mind and society: the hash realities. Nat Rev Neurosci 2008; 8: 885-95.

7 D'Souza DC, Perry E, MacDougall L, Ammerman Y, Cooper T, Wu YT, et al. The psychotomimetic effects of intravenous delta-9-tetrahydrocannabinol in healthy individuals: implications for psychosis. Neuropsychopharmacology 2004; 29: 1558-72.

8 Hardwick S, King L. Home Office Cannabis Potency Study. Home Office, 2008 (http://drugs.homeoffice.gov.uk/publication-search/cannabis/potency).

9 Potter DJ, Clark P, Brown MB. Potency of D9-THC and other cannabinoids in cannabis in England in 2005: implications for psychoactivity and pharmacology. J Forens Sci 2008; 53: 90-4.

10 Smith N. High potency cannabis: the forgotten variable. Addiction 2005; 100: $1558-9$.

11 World Health Organization. Schedules for Clinical Assessment in Neuropsychiatry (SCAN). WHO, 1992.

12 World Health Organization. The ICD-10 Classification of Mental and Behavioural Disorders. Clinical Description and Diagnostic Guidelines. WHO, 1992.

13 Bebbington PE, Nayani T. The Psychosis Screening Questionnaire. Int J Methods Psychiatr Res 1995; 5: 11-9.

14 Barkus EJ, Stirling J, Hopkins RS, Lewis S. Cannabis-induced psychosis-like experiences are associated with high schizotypy. Psychopathology 2006; 39 $175-8$.

15 Bossong MG, van Berckel BN, Boellaard R, Zuurman L, Schuit RC, Windhorst $A D$, et al. Delta 9-tetrahydrocannabinol induces dopamine release in the human striatum. Neuropsychopharmacology 2009; 34: 759-66.

16 Kapur S, Mizrahi R, Li M. From dopamine to salience to psychosis - linking biology, pharmacology and phenomenology of psychosis. Schizophr Res 2005: 79: 59-68.

17 Leweke FM, Schneider U, Radwan M, Schmidt E, Emrich HM. Different effects of nabilone and cannabidiol on binocular depth inversion in man. Pharmacol Biochem Behav 2000; 66: 175-81.

18 Morgan CJA, Curran HV. Effects of cannabidiol on schizophrenia-like symptoms in people who use cannabis. Br J Psychiatry 2008; 192, 306-7.

19 Home Office Research Development and Statistics Directorate. British Crime Survey, 2006-2007. Home Office (http://www.crimereduction. homeoffice.gov.uk/sta_index.htm).

20 Miettunen J, Tormanen S, Murray GK, Jones PB, Maki P, Ebeling $\mathrm{H}$, et al. Association of cannabis use with prodromal symptoms of psychosis in adolescence. Br J Psychiatry 2008; 192: 470-1. 